\title{
PENGEMBANGAN ALAT UKUR TINGGI BADAN MANUSIA SECARA OTOMATIS DENGAN ARDUINO
}

\author{
Yuli Hidayatul Anis 1*, Herry Sulendro Mangiri 2, Adi Nova Trisetiyanto 3 \\ SMK Budi Luhur 1, Universitas Ivet 2,3 \\ *yulii.aiss03@gmail.com
}

\begin{abstract}
ABSTRAK
Tujuan penelitian ini adalah 1). Menghasilkan sebuah alat ukur alternatif yang dapat digunakan tanpa harus ada bantuan dari orang lain. 2). Menguji keefektifan penggunaan dan sistem kerja yang sederhana, praktis, dan efisien sehingga memperoleh hasil yang tepat dan akurat dengan waktu yang lebih singkat. Metode yang digunakan dalam penelitian ini menggunakan penelitian Research and Development (R \& D). Dalam penelitian ini dilakukan dengan beberapa langkah, yakni: potensi dan masalah, pengumpulan data, desain produk, validasi desain, revisi desain, ujicoba produk, revisi produk, ujicoba pemakaian, revisi produk, produk masal atau produk akhir. Telah dibuat alat ukur tinggi badan manusia secara otomatis menggunakan sensor Ultrasonik HC-SR04 dengan Arduino Uno sebagai pusat pengendali sistem. Dengan adanya alat ini diharapkan dapat melakukan pengukuran secara cepat sehingga mempermudah pekerjaan dan menghemat waktu dalam pengukuran tinggi badan manusia, dengan hasil yang akurat.
\end{abstract}

Kata kunci: alat ukur tinggi badan, Arduino Uno, sensor Ultrasonik HC-SR04

\begin{abstract}
The purpose of this research is an activity that must be known before determining the research activity. The objectives of this research are as follows: (1) produces an alternative gauge that can be used without the need for help from others. (2) test simple, practical, and efficient work effectiveness and systems that produce accurate and accurate results with a shorter time. The purpose of this research is an activity that must be known before determining the research activity. The objectives of this research are as follows: (1) produces an alternative gauge that can be used without the need for help from others. (2) test simple, practical, and efficient work effectiveness and systems that produce accurate and accurate results with a shorter time .

Kata kunci: Measuring devices, arduino uno, HC-SR04 Ultrasound sensors.
\end{abstract}




\section{PENDAHULUAN}

Panjang dan tinggi merupakan salah satu besaran fisik yang sering diukur dalam berbagai keperluan yang membutuhkan data tinggi seseorang dalam sentimeter. Alat ukur tinggi badan yang beredar dipasaran kurang memungkinkan untuk mendapatkan data yang akurat, karena kebanyakan alat ukur tinggi badan yang beredar dipasaran masih bersifat manual. Mengukur tinggi badan seseorang, minimal harus ada operator alat yang tak lain seperti manusia, yang bertugas melakukan pengukuran sekaligus membaca data yang tampak pada hasil pengukuran tersebut. Hasil pembacaan skala pada alat ukur tinggi badan manual yang dilakukan manusia memiliki tingkat ketelitian dan ketepatan yang kurang dan belum lagi sampai terjadi human error.

Apabila yang ingin kita ukur hanya satu atau tiga orang mungkin tidak menjadi permasalahan, akan tetapi apabila orang yang akan diukur jumlahnya lebih dari 50 orang bahkan ratusan orang seperti kasus dalam suatu tes kesehatan yang dilakukan oleh suatu instansi dalam penerimaan pegawai baru, hal ini tentunya akan sangat merepotkan dan banyak menghabiskan waktu.

Apabila ingin mengukur tinggi badan menggunakan meteran yang manual, seseorang harus benar-benar teliti dalam melakukannya, karena didalam pembacaan alat ukur meteran manual masih menggunakan analog dan dalam pembacaannya biasanya terjadi perselisihan pembacaan antara satu orang dengan orang yang lain karena skala atau keakuratannya yang berbeda.

\section{METODE PENELITIAN}

Pada penelitian dan pengembangan alat ukur tinggi badan manusia secara otomatis dengan arduino ini menggunakan pendekatan penelitian Research and Development (R \& D). Metode penelitian dan pengembangan atau dalam bahasa inggrisnya
Research and Development adalah metode penelitian yang digunakan untuk menghasilkan produk tertentu, dan menguji keefektifan produk tersebut.

Prosedur pengembangan yang digunakan dalam penelitian ini mengunakan metode research and Development (R\& D). langkah-langkah penelitian dan pengembangan ditunjukan pada gambar berikut.

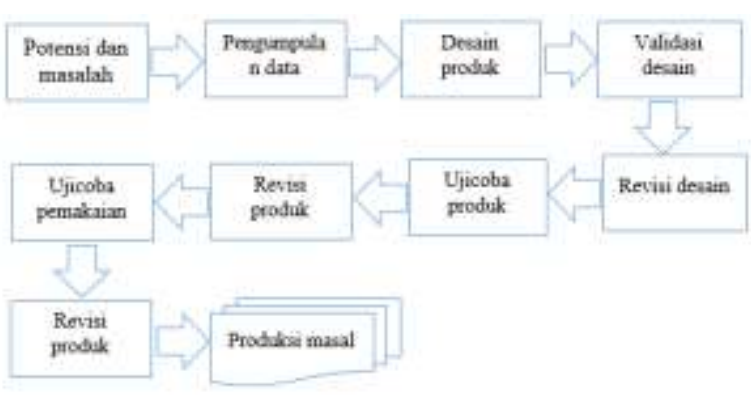

Gambar 1. Langkah-langkah Penggunaan Metode Research and Development (RnD)

Skematik rangkaian alat pengukur tinggi badan ini adalah gambaran suatu rangkaian yang memberikan cara kerja yang detail, mulai dari simbol sampai dengan koneksi rangkaian satu ke rangkaian lainnya, yang terlihat pada gambar berikut.

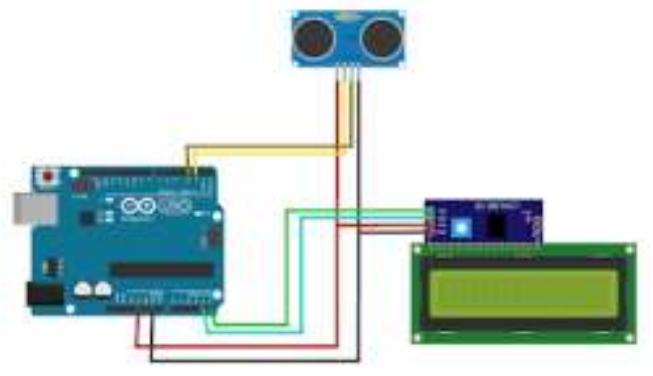

Gambar 2. Skematik rangkaian alat ukur tinggi badan otomatis Keterangan :

a) Trig/Triger dihubungkan dengan pin 2 Arduino 
b) Echo dihubungkan dengan pin 3 Arduino

c) SDA dihubungkan ke pin A4/SDA Arduino

d) SCL dibungkan ke pin A5/SCL Arduino

e) $V C C$ dihubungkan ke $5 \mathrm{~V}$

f) GND dihubungkan ke GND Arduino

Perancangan Cara Kerja Alat Pengukuran Tinggi Badan Otomatis.

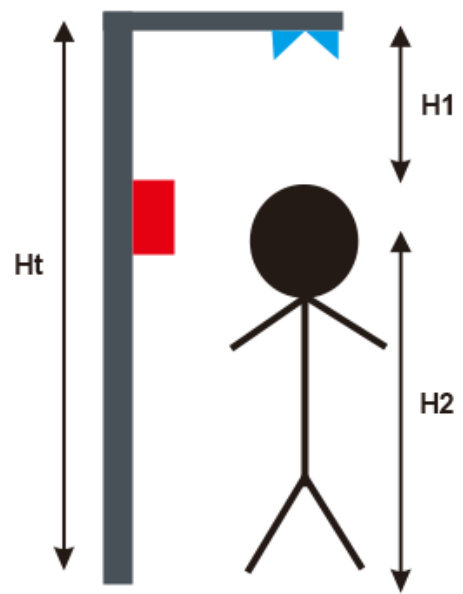

Gambar 3. Sketsa cara kerja alat pengukuran tinggi badan otomatis

Pada gambar diatas merupakan sketsa alat pengukuran tinggi badan otomatis berbasis arduino yang menggunakan sensor ultrasonik. Sensor ultrasonik di pasang sebagai rangkaian sensor. Dan ketika sinyal mengenai benda penghalang maka sinyal ini di pantulkan dan diterima oleh rangkaian receiver (penerima) dikirimkan ke rangkaian mikrokontroller untuk selanjutnya diolah untuk menghitung tinggi terhadap benda di depannya. Untuk mengukur tinggi badan seseorang dengan menggunakan sensor ultrasonik agar dapat mengukur dengan sesuai menggunakan pengitungan seperti berikut:

$$
H 2=H t-H 1
$$

Keterangan :

1) $\mathrm{H} 2$ adalah objek seseorang yang akan diukur

2) Ht adalah tinggi sensor dari permukaan tanah

3) H1 adalah jarak sensor ke kepala objek

Flowchart adalah sebuah diagram dengan simbol-simbol grafis yang menyatakan aliran algoritma atau proses yang menampilkan langkah-langkah yang disimbolkan dalam bentuk kotak, beserta urutannya dengan menghubungkan masing masing langkah tersebut menggunakan tanda panah. Diagram ini bisa memberi solusi selangkah demi selangkah untuk penyelesaian masalah yang ada di dalam proses atau algoritma tersebut. Dalam penulisan flowchart dikenal dua model, yaitu sistem flowchart dan program flowchart. Program flowchart adalah bagan yang memperlihatkan urutan dan hubugan proses dalam suatu program. Berikut adalah diagram alir (flowchart) :

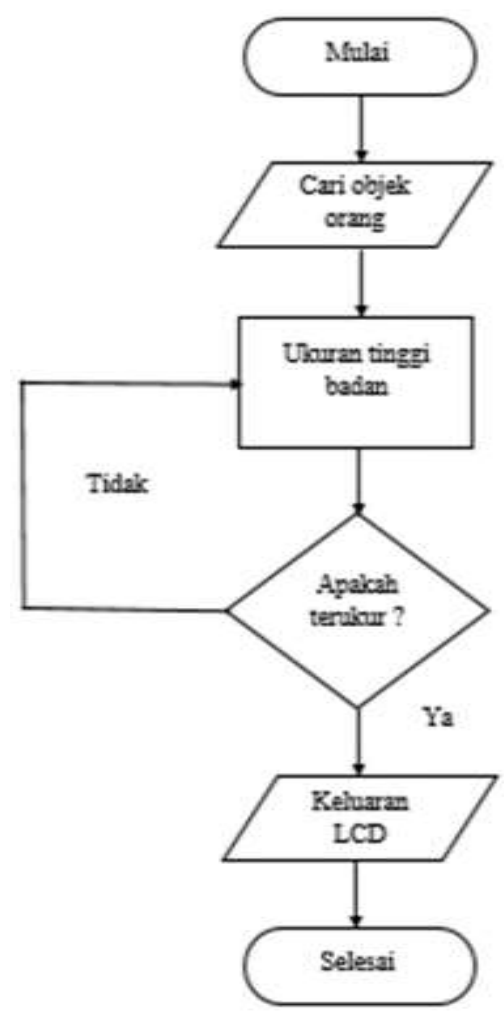

Gambar 4. Gambar Flowchart sistem. 
Dalam melakukan penelitian ini menggunakan beberapa metode pengumpulan data, antara lain :

1. Observasi

Observasi dilakukan dengan cara mengamati secara langsung sistem monitoring pada alat ukur tinggi badan yang sudah ada sebelumnya dan dari hasil observasi ini dapat diperoleh gambaran fiturfitur apa saja yang harus ada dalam sistem yang akan dibuat agar sistem monitoring ini dapat berfungsi lebih baik.

2. Kuesioner

Kuesioner merupakan cara mengumpulkan data secara tidak langsung. Kuesioner berupa pertanyaan yang diberikan kepada responden. Hal ini dimaksudkan untuk mengetahui respon user terhadap aspek usability pada perangkat yang akan dikembangkan.

Menurut Suharsimi Arikunto (2002: 144) validitas adalah suatu ukuran yang menunjukan tingkat-tingkat atau kesahihan suatu instrument. Menurut Sugiyono (2012: 173), Instrumen dikatakan valid bila alat ukur yang digunakan dapat mengukur data dengan valid. Agar penelitian pengembangan ini valid, maka peneliti menambahkan angket dimana ahli materi dan ahli media mengisi sesuai dengan pertanyaan yang disediakan. Validasi instrumen untuk ahli materi dan ahli media dilakukan melalui konsultasi dan meminta penilaian kepada para ahli yang memiliki keahlian tentang materi yang akan diuji dan kriteria media pembelajaran. Skala tersebut meliputi (1): Sangat tidak setuju/sangat tidak layak, (2) : Tidak sesuai/tidak layak, (3) : Sesuai/layak, (4) : Sangat sesuai/sangat layak.

Teknik analisis data merupakan cara untuk mengetahui hasil penelitian yang dilakukan. Teknik analisa data yang dilakukan pada penelitian ini adalah teknik analisa kuantitatif yang bersifat penilaian menggunakan angka. Persentase dimaksudkan untuk mengetahui status sesuatu yang dipersentasekan dan disajikan tetap berupa persentase. Rumus perhitungan kelayakan menurut Sugiyono (2013: 559) adalah sebagai berikut.

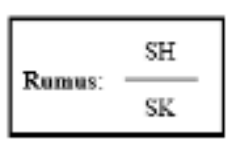

Keterangan:

SH : Skor Hitung

SK : Skor Kriteria atau Skor Ideal

Hasil perhitungan data selanjutnya dibuat dalam bentuk persentase dengan dikalikan $100 \%$.

\begin{tabular}{|l|l|}
\hline Skor dalam presentase & Kategori Kelayakan \\
\hline$<40 \%$ & Tidak Baik/Tidak Layak \\
\hline $40 \%-55 \%$ & Kurang Baik/Kurang Layak \\
\hline $56 \% 75 \%$ & Cukup Baik/Cukup Layak \\
\hline $76 \%-100 \%$ & Baik Layak \\
\hline
\end{tabular}

Tabel 1. Kategori Persentase Kelayakan

Angket yang digunakan dalam peneitian ini adalah angket penilaian atau tanggapan dengan bentuk jawaban dan keterangan penilaian, yaitu. (1): Sangat tidak setuju/sangat tidak layak, (2) : Tidak sesuai/tidak layak, (3) : Sesuai/layak, (4) : Sangat sesuai/sangat layak.

\section{HASIL DAN PEMBAHASAN}

Pengembangan alat ukur tinggi badan Manusia Secara Otomatis Dengan Arduino berupa alat ukur tinggi badan yang dimodifikasi dengan sensor ultrasonik. Produk awal yang dihasilkan dinamakan "Pengembangan Alat Ukur Tinggi Badan Manusia Secara Otomatis Dengan Arduino" untuk memberikan efektivitas serta keefesienan dalam kegiatan tes dan pengukuran. Dengan demikian "Pengembangan Alat Ukur Tinggi Badan Manusia Secara Otomatis Dengan Arduino" diharapkan dapat digunakan sebagai media 
alat ukur yang memberi kemudahan dalam kegiatan tes dan pengukuran dalam rekrutmen atlet maupun mengetahui potensi atlet guna mengefisienkan dalam proses melatih.

Uji coba dilakukan kepada responden Remaja Karang Taruna dan Remaja Desa Banjarejo. Uji coba dilakukan dalam 1 pertemuan. Kondisi selama uji coba secara keseluruhan dapat dijabarkan sebagai berikut. (a) Kondisi penjelasan pemakaian alat "Pengembangan Alat Ukur Tinggi Badan Manusia Secara Otomatis Dengan Arduino" responden terlihat senang, antusias, penasaran dan bertanyatanya pada peneliti ketika diberikan penjelasan awal mengenai pamakaian alat ukur. Penjelasan prosedur pemakaian alat pada responden guna memudahkan testee dalam menggunakan alat "Pengembangan Alat Ukur Tinggi Badan Manusia Secara Otomatis Dengan Arduino". (b) Kondisi saat pengisian angket, responden dibantu oleh pendamping dan peneliti. Proses pengambilan jawaban dilakukan dengan menanyakan kepada responden yang bersangkutan.

Tabel 2. Pengujian pengukuran sistem tinggi badan

\begin{tabular}{|c|c|c|c|c|}
\hline \multicolumn{2}{|c|}{ Pengujian ke } & \multirow{2}{*}{$\begin{array}{c}\text { Pengukuran } \\
\text { tinggi badan } \\
\text { manual }\end{array}$} & \multirow{2}{*}{$\begin{array}{c}\text { Pengukuran } \\
\text { tinggi badan } \\
\text { otomatis }\end{array}$} & \multirow{2}{*}{ Error \% } \\
\hline No. & Nama & & & \\
\hline 1. & Rahma & 165 & 165 & 0 \\
\hline 2. & Dila & 157 & 157 & 0 \\
\hline 3. & Mujib & 164 & 165 & 0,0060 \\
\hline 4. & Ayu & 162 & 162 & 0 \\
\hline 5. & Nurul & 168 & 167 & 0,0059 \\
\hline 6. & Kus Indarto & 173 & 173 & 0 \\
\hline 7. & Yarti & 156 & 157 & 0,0064 \\
\hline
\end{tabular}

Pengujian alat pengukuran tinggi badan otomatis berbasis mikrokontroller ini dilakukan dengan cara meletakkan sensor diatas tiang setinggi $200 \mathrm{~cm}$ dan kemudian objek seseorang berdiri di bawah sensor tersebut kemudian dilakukan perbandingan dengan hasil dari pembacaan LCD pada alat dengan pengukuran tinggi badan secara manual yang ada di pasaran untuk sebagai acuan.

tinggi badan dengan alat yang telah di rancang dan akan dibadingkan dengan pengukuran tinggi badan secara manual.

Berikut ini hasil pengujian dan gambar saat menghitung tinggi badan seseorang ;

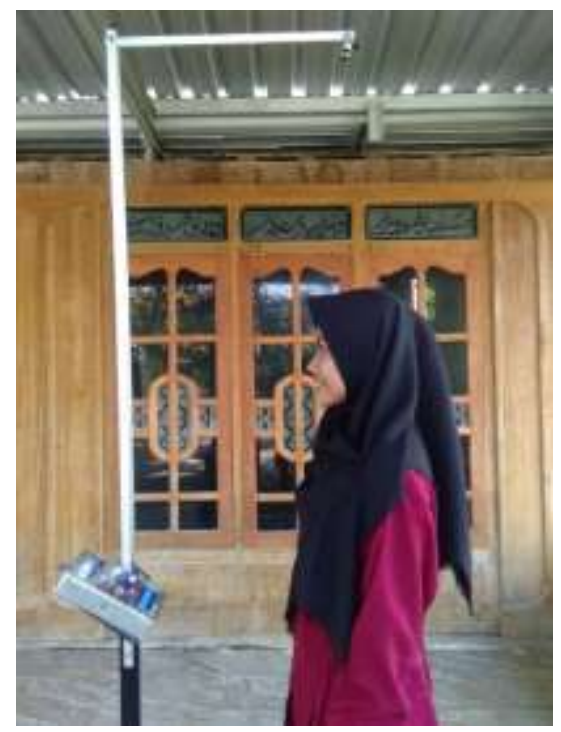

Gambar 5. proses pengukuran tinggi badan.

Rumus perhitungan alat pengukuran tinggi badan otomatis ;

$$
H 2=H t-H 1
$$

Keterangan :

H2 adalah objek seseorang yang akan diukur Ht adalah tinggi sensor dari permukaan tanah H1 adalah jarak sensor ke kepala objek

Rumus error :

Error $\%=\frac{\mathrm{Uji}_{\mathrm{j} \text { alat yang dibuat }- \text { Hasil uji alat lain }}}{\text { Hasil alat uji lain }} \times 100 \%$

Pada alat pengukur tinggi badan otomatis ini mikrokontroler AT Mega8535 merupakan otak semua proses hardware dan software. Mikrokontroler akan memproses semua data 
yang masuk kedalam sebuah program yang telah dibuat. Untuk mengetahui tinggi badan seseorang, mikrokontroler AT Mega8535 akan memproses input dari sensor. Dalam proses menghitung tinggi badan, hasil dapat diperoleh dari tinggi sensor $(200 \mathrm{~cm})$ dikurangi jarak pengukuran sensor ke bagian kepala. Kemudian hasil yang diperoleh ditampilkan pada display LCD.

Rangkaian mikrokontroller ATMega32 di program dengan menggunakan bahasa program Arduino UNO. Untuk kode perintahnya dijelaskan dibawah dan untuk gambar proses pemrograman ditunjukkan pada gambar 6. untuk program keseluruhan terletak pada lampiran.

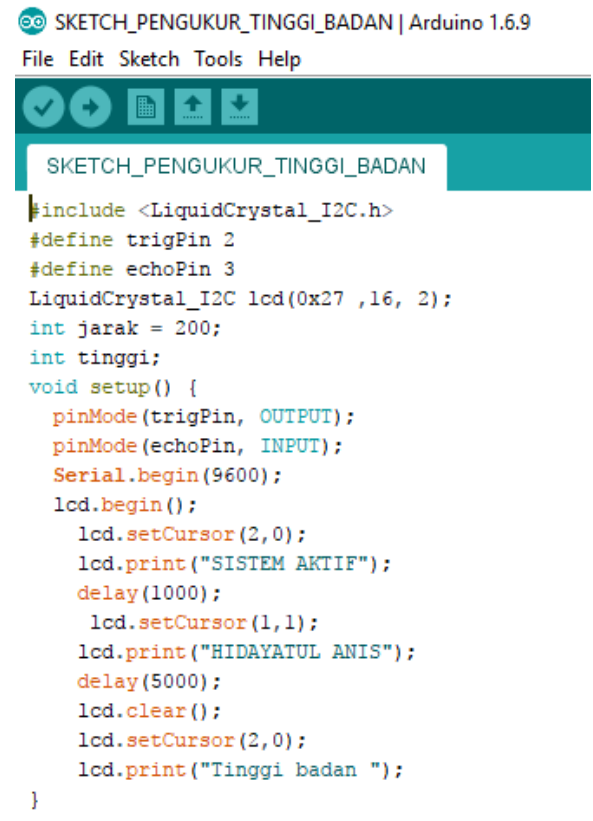

Gambar 6. Tampilan proses program mikrokontroller

Pengukuran mempunyai tujuan untuk mengetahui apakah tinggi badan kita, Pengukuran juga mempunyai tujuan untuk mengetahui kinerja dari alat tinggi badan yang telat dirancang apakah sesuai dengan spesifikasi dari sensor yang digunakan atau tidak, karna dalam pemogram alat tinggi badan tersebut sangatlah susah untuk menyesuaikan kalibrasi yang benar - benar akurat dan tepat. Pada awal Pengembangan
Alat Ukur Tinggi Badan otomatis ini didesain dan diproduksi menjadi sebuah produk awal berupa alat ukur untuk semua umur dalam proses tes dan pengukuran ke depan. Penelitian ini menyajikan hasil pengukuran tinggi badan yang seharusnya dimiliki oleh testee. Proses pengembangan melalui prosedur penelitian dan pengembangan. Melalui beberapa perencanan, produksi dan evaluasi, kemudian produk dikembangkan dengan program mikrokontroler arduino uno, Selanjutnya tahap penelitian dilakukan dengan uji coba produk.

Pengujian alat dimaksutkan untuk mengetahui apakah sistem yang telah dibuat sesuai dengan apa yang telah dirancang. Proses pengujian ini meliputi pengukuran tinggi badan dengan alat yang telah di rancang dan akan dibadingkan dengan pengukuran tinggi badan secara manual.

Pengujian sistem secara keseluruhan meliputi dua bagian;

a. alat pengukuran tinggi badan otomatis dilakukan dengan cara membandingkan hasil pengukuran alat yang telah dirancang dengan pengukuran tinggi badan yang ada dipasaran atau pengukuran tinggi badan secara manual. b. Pengujian kestabilan alat dengan cara membandingkan hasil pengukuran alat tinggi badan otomatis (yang ditampilkan pada LCD) dengan alat pengukuran tinggi badan secara manual yang berada di pasaran.

\section{PENUTUP}

Berdasarkan penelitian yang telah dilakukan untuk pembuatan alat ukur tinggi badan manusia secara otomatis dengan arduino maka dapat diambil kesimpulan sebagai berikut:

1. Alat Ukur Tinggi Badan Manusia Secara Otomatis Dengan Arduino yang dirancang dan dibuat untuk mendeteksi tinggi badan seseorang terbukti dapat digunakan sebagai pengganti alat ukur tinggi badan manual.

2. Memberikan kemudahan untuk mengukur tinggi badan manusia yang sebelumnya 
masih mengukur tinggi badan secara manual kini telah dapat dilakukan secara digital atau otomatis.

3. Dalam pemasangan alat dan mekanis membutuhkan tingkat ketelitian yang tinggi supaya Alat Ukur Tinggi Badan Manusia Secara Otomatis Dengan Arduino dapat beroperasi dengan baik.

\section{DAFTAR PUSTAKA}

Arikunto, Suharsimi. (2002). Prosedur Penelitian: Suatu Pendekatan Praktek. Edisi Revisi V. Cetakan Kedua belas. Jakarta: Rineka Cipta.

Berbage Ilmu. 2017. "https://berbageilmu.blogspot.com/2 017/10/membuat-alat-ukur-tinggibadan-dengan.html". ( Diakses pada Jum'at, 05 Juni 2020).

Misbahuddin Adonis. 2017 "Rancangan Alat Pengukuran Tinggi Badan Otomatis Berbasis Mikrokontroller" Universitas 17 Agustus 1945 Surabaya.

Nurahman Fahmi. 2010 "Rancang Bangun Pengukur Tinggi Badan Otomatis Berbasis Mikrokontroler Atmega8535”. Universitas Sebelas Maret Surakarta.

Sugiyono. (2012). Metode Penelitian Pendidikan Pendekatan Kuantitatif Kualitatif Dan R\&D. Bandung: Penerbit Alfabeta.

Sugiyono. (2015). Metode Penelitian Pendidikan Pendekatan Kuantitatif Kualitatif Dan R\&D. Bandung: Penerbit Alfabeta.
4. Keluaran dari Alat Ukur Tinggi Badan Manusia Secara Otomatis Dengan Arduino ini adalah sebuah teks pada LCD 16x2. 